\title{
The mental health market
}

\section{Recent government policy and legislation}

\author{
Paul Ward
}

\begin{abstract}
When introduced into the NHS in 1991, the internal market world of purchasers and providers was greeted with considerable cynicism by many working in the mental health field. Three years on, this cynicism has to a large extent been supplemented by elther support or hostilly about the changes dependent upon indlvidual experiences. However a more detached analysis suggests a more balanced picture of the impact of the internal market beginning to emerge.
\end{abstract}

\section{Policy context}

The beginnings of the internal market in the UK healthcare system can probably be traced to Professor Alain Enthoven's study of the NHS in 1985. Drawing on his experience and knowledge of health maintenance organisations in the US, Enthoven advocated trading between district health authorities, and the introduction of financial incentives to reward increases in service. Although, falling short of arguing for separation between purchasing and providing, this was a logical next step, which four years later saw the light of day in the White Paper Working for Patients.

The White Paper envisaged district health authorities (DHAs) and GP fund-holders commissioning health services from provider hospital and community services, most of which would become self governing NHS trusts within a five year period (Department of Health, 1989a).

These proposals were followed almost immediately in autumn 1989, by a second White Paper Caring for People which set out parallel proposals for the commissioning of individual packages of care, and assigned a lead community care responsibility for mental health to social services departments. (Department of Health, 1989b).

Implementation of these changes was set for April 1991; however, with less that nine months to go, many of the key community care changes were delayed for two years to enable further preparation to take place.

In the run up to, and immediately after April 1991, much attention both within the NHS and within the press was focused upon the establishment of NHS trusts, with the result that relatively little attention was paid to the development of the commissioning function. This has over the last 12 months been redressed with the continued growth of GP fund-holders, the ministerial emphasis placed on the importance of commissioning (NHSME, 1993), and the current NHS functions and manpower review (NHSME, 1994). However, in many parts of the UK, commissioning is still relatively underdeveloped, and even where progress has been made, considerably more remains to be achieved, as the internal market continues to evolve.

Any assessment of the impact of the purchaser/provider arrangements in the NHS must acknowledge that the internal market has from the beginning always been particularly well suited to services organised in single episodes of in-patient care. Indeed, in the run up to implementation in 1991, the most quoted example of how the market would work depicted NHS managers buying and selling hip replacement operations. That the market would work in areas such as acute surgery was seldom in doubt; however, its success in the mental health field was much more open to doubt.

\section{Implications for individual psychiatric practice}

The impact of the changes on psychiatric practice has been mixed. On the positive side, the attention paid in the reformed NHS to clinical audit and to reducing costs has provided an environment in which the cost effectiveness of individual clinical practice has come under scrutiny. Aided by the development of comparative information between providers, it is particularly important that emphasis is placed equally upon effectiveness and cost, and assuming this can bring benefits to individual patients, and also to the broader patient population as a whole, if changes as a result of this work allow money to be released for new services.

There are, however, dangers if too heavy an emphasis is placed upon the financial considerations. This was well illustrated by the difficulties which the Cassell Hospital faced in 1991 and 
1992, where there appeared to be a trend of clinical practice in referring services changing such that many people were treated locally without being referred to the Cassell (Ward. 1993). It is almost certain, that in many cases the motivation for changing clinical and referring practice was financially driven, rather than by an assessment based upon likely treatment outcome.

Within primary health care services, the effect on clinical practice has also been mixed. The establishment of a distinct purchasing function has added impetus to the developing role of GPs and mental health primary health care teams. In assessing the level at which care is most appropriately provided, Commissioners have had a substantial role to play in questioning existing practice, and working with both primary and secondary care providers to improve services. The integration of primary and secondary care commissioning in the growing number of FHSA/ DHA Health Commissions is likely to underpin this.

On a less positive note, more needs to be done to develop the role of GP fund-holders. Currently, fund-holders only have partial funding responsibility for mental health services, such that there is a financial disincentive to treat people in a community setting. Use of acute mental health services is free to fund-holders while use of some community mental health services is liable to be paid for from fund-holder allocations. The potential impact which this might have on clinical practice is to distort it in a way which might not benefit the individual.

\section{Implications for users of mental health services}

The implications of the legislative changes on service users are also difficult to assess. The theory behind the reforms was that they would result in users in general being empowered through the development of the commissioning function, and through the development of user sensitive providers. This would particularly benefit users who had historically faced institutional discrimination. The reality in the mental health field appears to be that in those areas where commissioning is well developed, and where providers place emphasis on work with users, some progress has been made. However, where these ingredients do not exist, progress has been disappointingly slow.

The use of competition has brought mixed results for mental health users. In some areas where providers are in close proximity to each other, the use of competition has undoubtedly brought benefits for users by giving them and commissioners the opportunity to use an alter- native service. In other areas however, where choice may be limited, the limitations on geographical mobility which many users face mean that there are only very limited benefits derived from competition. This is further complicated by the need to ensure that where service changes do occur they are well publicised, and if possible, considered in advance with users in order to avoid their disenfranchisement.

When originally introduced, the reforms were promoted as offering an improvement in the choice offered to patients in general. In the mental health field, this increase in choice has not lived up to expectations, particularly in relation to access to specialist services. Prior to 1991, the primary obstacle to be negotiated in accessing specialist services was either a GP or a psychiatrist. In the 'post White Paper' NHS, many such referrals are now considered as requests for extra contractual referral (ECR) funding. As such, in an environment where constant attention is paid to competing priorities, such referrals may often not be funded. Guidance issued at the beginning of 1993 compelling DHAs to fund tertiary referrals has probably helped to minimise this as a problem; however not only does this guidance not cover non medical referrals, but also it is clear that there are ways of circumventing these with the result that choice for service users is reduced.

\section{Implications for working arrangements with purchasers and providers}

In assessing the impact of the reforms on purchasers and providers in mental health service systems, it is important to recognise that different ways of working have developed across the country. Some areas are characterised by arms length relationships, while in others a more collaborative approach has developed (NHSME, 1993).

Relationships have also changed over time. Initially, purchasers and providers often had distant and sometimes conflictual relationships with providers. Increasingly however, as the internal market matures, these are beginning to be replaced by ones which emphasise the benefits of closer joint working.

An important element of the change in relationship, particularly in the mental health field is the development of a more sophisticated view about how to use competition. The long-term nature of many mental health services, together with the importance attached to coordination of services, limits the application of competition around individual service areas such as inpatients, or community psychiatric nurses. As such, some purchasers have focused competition at service system level, by for example 
inviting tenders for entire district-wide mental health services. By in the first instance only changing the senior management in affected services, this approach not only recognises the need to ensure continuity of clinical service to users and retain clinical expertise, but also necessitates a longer term close working relationship between purchaser and provider.

This work has been paralleled in other districts in which contracts of longer than one year have been developed in order to provide a stable framework in which services can develop (SE London Health Authority, 1993). This has also resulted in a reduction in the amount of management time required to negotiate and agree contracts, overcoming one of the criticisms of the internal market.

Experience of commissioning mental health services in South East London since 1991 has suggested that neither a wholly competitive, nor a wholly collaborative relationship is entirely appropriate. A key challenge for commissioners is to develop an approach which enables value for money to be constantly optimised and equal opportunity to be given to providers to bid for new services, while maintaining and developing a close working relationship.

\section{Concluding remarks}

The introduction of purchasing and providing into the NHS has generated an increased awareness of cost, and of cost differences between providers. While considerable care needs to be taken in looking at differences, this does nevertheless provide an important opportunity for comparison and audit with the aim of reducing the costs of expensive providers where this does not bring about demonstrable benefits for service users. In so doing this provides a valuable means of releasing resources for new mental health developments.

Mental health services have clearly been among the prime beneficiaries of improved husbandry of resources by commissioners, and of any new monies made available since 1991 . Work undertaken by the National Association of Health Authorities and Trusts (1992) evaluating the impact of commissioning decisions taken in 1991 and 1992 revealed that a substantial proportion of DHAs had given priority to mental health services which had resulted in increases in funding.

In conclusion, a verdict on the first three years of the NHS internal market would probably have to conclude that where commissioning is well developed, where responsive providers exist, and where collaborative working relationships have developed, the reforms are beginning to bring benefits in terms of quality and value for money. However, in some parts of the country these ingredients do not currently exist. Commissioning as a distinct function is barely three years old, and the challenge for the next three years is to ensure that it continues to evolve at least the current pace, and that it evolves at a more consistent pace across the country as a whole.

\section{References}

DEPARTMENT OF HEALTH (1989a) Working for Patients. HMSO. - (1989b) Caring for People. HMSO.

ENTHOVEN, A.C. (1985) Reflections on the Management of the NHS. Nuffield Provincial Hospitals Trust.

National Association of Health Authorttes and Trusts (1992) Patterns of Priortiles: a study of the purchasing and rationalising policies of health authorities. NAHAT Research Paper.

NHSME (1993) Purchasing for Health: a framework for action.

- (1994) Progress Report: managing the new NHS.

SOUTH EAST LONDON HEALTH AUTHORTTY (1993) Moving Together on Health: purchasing intentions for 1994/1995. London: SELHA.

WARD, P. (1993) Purchasing for mental health. The Health Summary, $x$, 3-4.

Paul Ward, Director of Corporate Business, Lambeth, Southwark and Lewisham Health Commission, 1 Lower Marsh, London SE1 7RJ 